\title{
Immunoglobulins in Serum: A New Prognostic and Diagnostic Biomarker in Oral Potentially Malignant Disorder-Oral Submucous Fibrosis
}

\author{
${ }^{1}$ Kalari K Rakheerathnam, ${ }^{2}$ Balasubramaniam Saravanan, ${ }^{3}$ Sivasithamparam N Devaraj
}

\begin{abstract}
Aim: Tissue fibrosis can be considered as a component of normal healing process in response to various kinds of injury. It involves the recruitment of immune cells and inflammatory molecules to the site of injury and accumulation and reorganization of extracellular matrix components. The stress exerted during fibrogenesis leads to the activation of immune cells. Based on these, we intended to study the level of serum immunoglobulins at various stages of a precancerous condition of oral mucosa called oral submucous fibrosis (OSMF).
\end{abstract}

Materials and methods: The major serum immunoglobulin levels, namely, immunoglobulin G (IgG), Immunoglobulin A $(\lg A)$, Immunoglobulin $M(\lg M)$, and Immunoglobulin $E(\lg E)$, were analyzed by chemiluminescence immunoassay. The results obtained were subjected to analysis of variance and Tukey-Kramer multiple comparisons to reveal the statistical significance of the disease.

Results: The present study reported a significantly high level of $\lg \mathrm{G}, \lg \mathrm{A}, \lg \mathrm{M}$, and $\lg \mathrm{E}$ in all stages of OSMF when compared with healthy individuals.

Conclusion and clinical significance: Thus, the alterations in the routine immunological analysis observed in the present study could be utilized both as prognostic and diagnostic marker in case of oral potentially malignant disorder, especially OSMF.

Keywords: Biomarker, Oral submucous fibrosis, Serum immunoglobulins.

How to cite this article: Rakheerathnam KK, Saravanan B, Devaraj SN. Immunoglobulins in Serum: A New Prognostic and Diagnostic Biomarker in Oral Potentially Malignant DisorderOral Submucous Fibrosis. World J Dent 2018;9(2):106-110.

Source of support: University Grants Commission - Basic Scientific Research (UGC-BSR), New Delhi, India.

Conflict of interest: None

\section{INTRODUCTION}

Although the expression of immunoglobulins by cancer cells was known for years, the concept of immunoglobulin

\footnotetext{
${ }^{1,3}$ Department of Biochemistry, University of Madras, Chennai Tamil Nadu, India

${ }^{2}$ Department of Oral and Maxillofacial Surgery, Tamilnadu Govt. Dental College and Hospital, Chennai, Tamil Nadu, India

Corresponding Author: Sivasithamparam N Devaraj, Department of Biochemistry, University of Madras, Chennai, Tamil Nadu, India e-mail: niranjali@yahoo.com
}

production only by B-lymphocytes and plasma cells was challenged, when many non-lymphoid lineage cells, such as breast cancer cells, colorectal cancer cells, papillary thyroid cancer cells, and prostate cancer cells were found to have the ability to produce immunoglobulins. Studies conducted so far revealed that immunoglobulins secreted during cancer were able to promote growth and survival of tumor cells and also found to correlate the proliferation markers and tumor grades. ${ }^{1}$ Immunity plays a major role in the development of any disease, and thus immunity can be considered as the state of protection from the disease. Blood is one of the important and versatile body fluids in our system and attempts to investigate the serological parameters help not only in the early diagnosis but also as prognostic markers during the disease progression.

It has been reported that the immunological abnormalities are higher in patients with head and neck cancers when compared with other types, such as breast, bronchus, colon, or bladder. ${ }^{2}$ In this study, we designed and performed a set of serological experiments to investigate the role of immunoglobulins in a precancerous condition of oral mucosa called OSMF. The incidence of OSMF is high in India, especially in Chennai, when compared with other precancerous and cancerous conditions. The incidence of malignancies ranges from 3 to $6 \%$. We localized our study in the metro city Chennai where this disease is predominant in the younger generation due to the lifestyle-related habits, such as the use of areca nut or its commercially available form called pan masala. ${ }^{3,4}$

\section{MATERIALS AND METHODS}

Patients were selected from those who were attending the Outpatient Department of Oral Medicine and Radiology of Tamil Nadu Government Dental College and Hospital, Chennai, Tamil Nadu, India. The protocol for the use of human serum samples was approved by the Institutional Ethical Committee.

The study comprised 51 individuals with OSMF and 17 normal healthy, age- and gender-matched individuals. Patients who belong to Chennai region alone were included in the study. The OSMF patients with any systemic disorders and normal healthy individuals with habits of areca nut chewing or use of pan masala were excluded from the study. An informed consent was 
Immunoglobulins in Serum

collected from each patient who participated in the study. Information related to the habits of each individual, such as type of product used, duration of habit, and number of packets used per day was collected from those who participated in the study. Grouping of patients was done based on their mouth opening. ${ }^{5}$

- Group I (control) $\rightarrow 40 \mathrm{~mm}$

- Group II (Stage I) -30-40 mm

- Group III (Stage II)-20-30 mm

- Group IV (Stage III) - <20 mm.

\section{Blood and Serum Collection}

About $5.0 \mathrm{~mL}$ of blood was collected aseptically using coagulant-coated vacutainer tubes with gel, from each patient and was allowed to clot at room temperature. It was then centrifuged at 3,000 rpm for 10 minutes and the serum which was separated above the gel was collected in fresh Eppendorf tubes and was used to carry out the following experiments.

\section{Immunological Parameters}

Serum levels of IgG, IgA, IgM, and IgE were determined by chemiluminescence immunoassay (ADVIA Centaur).

\section{Statistical Analysis}

Statistical analysis of serum levels of various immunoglobulins of the four studied groups was done by analysis of variance (ANOVA) and Tukey-Kramer multiple comparisons.

\section{RESULTS}

The study comprised 68 patients in which 51 were OSMF cases and 17 were normal healthy, age- and gender-matched individuals. The subjects included in the study were in the age range of 20 to 60 years with mean age of 40 years. A male predominance was noted, with 59 patients being male and only 9 female patients. The age of patients who belong to the different stages of OSMF and healthy individuals is given in Table 1 . In the
Table 1: Age distribution of OSMF and healthy individuals

\begin{tabular}{lllll}
\hline & \multicolumn{4}{c}{ Number of patients } \\
\cline { 2 - 5 } Age (years) & Group I & Group II & Group III & Group IV \\
\hline $20-30$ & 4 & 7 & 4 & 5 \\
$31-40$ & 7 & 4 & 9 & 6 \\
$41-50$ & 4 & 0 & 5 & 3 \\
$51-60$ & 2 & 0 & 4 & 4 \\
\hline
\end{tabular}

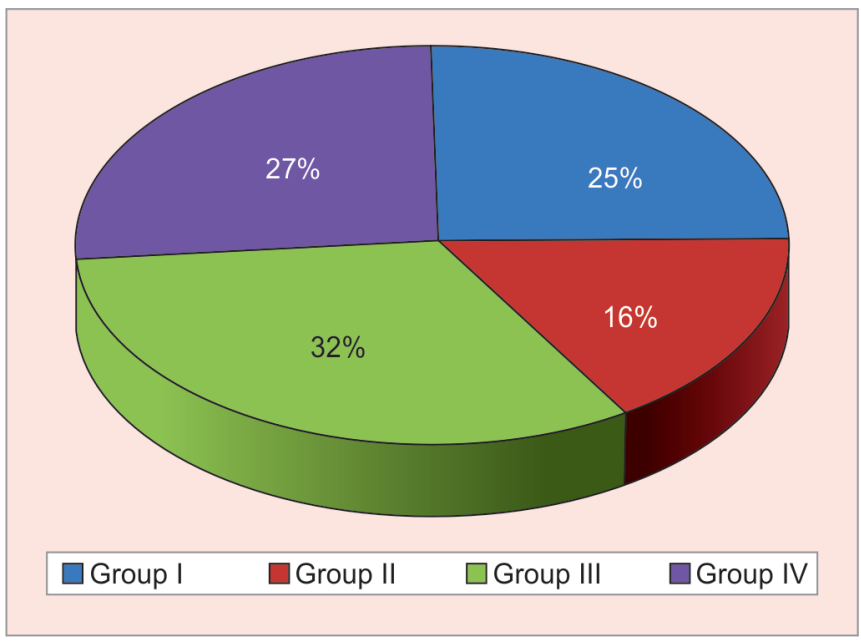

Graph 1: Percentage of patients belonging to each clinical stage

present study, the maximum incidence of the disease was observed in subjects who belong to the age group of 31 to 40 years. Similarly, the maximum number of patients (32\%) included in the study belongs to group III (Graph 1).

Comparisons of mean serum IgG, IgA, IgM, and IgE of the four groups were done using ANOVA and intergroup comparisons were done by utilizing Tukey-Kramer multiple comparisons. The "F" values observed in both the statistical methods were statistically significant $(\mathrm{p}<0.01$ or $\mathrm{p}<0.05)$. The results of Tukey-Kramer multiple comparisons showed that all the mean values differ significantly from each other (Table 2).

The following inferences were obtained from the statistical correlation done. A significantly high level of serum IgG level was observed in group IV $(2,064.94)$ when compared with group I $(1,472.82)$. Groups III $(1,755.40)$ and II

Table 2: Results of ANOVA and Tukey-Kramer test for multiple comparisons of mean values for immunoglobulins

\begin{tabular}{|c|c|c|c|}
\hline \multirow[b]{2}{*}{ Immunoglobulins } & \multicolumn{3}{|c|}{ Subgrouping of means } \\
\hline & Set 1 & Set 2 & Set 3 \\
\hline $\operatorname{lgG}(\mathrm{mg} / \mathrm{dL})$ & Group IV (2064.94) & Group II $(1,614.18)$ & Group I $(1,472.82)$ \\
\hline$F=19.17^{*}$ & & Group III $(1,755.40)$ & \\
\hline $\lg A(m g / d L)$ & Group IV (633.94) & Group III (449.77) & Group I (292.76) \\
\hline$F=27.25^{*}$ & & & Group II (315.72) \\
\hline $\operatorname{lgM}(\mathrm{mg} / \mathrm{dL})$ & Group IV (303.11) & Group II (157.14) & Group I (130.47) \\
\hline$F=11.60^{*}$ & & Group III (189.45) & \\
\hline $\lg E(\mathrm{mg} / \mathrm{dL})$ & Group I (80.76) & Group II (108.72) & Group IV (148.33) \\
\hline$F=23.45^{*}$ & & Group III (120.00) & \\
\hline
\end{tabular}

Mean values of serum IgG, IgA, IgM, and IgE levels obtained in each group are expressed as mg/dL; * Significant at $p<0.01$; Mean values between different sets are significantly different 

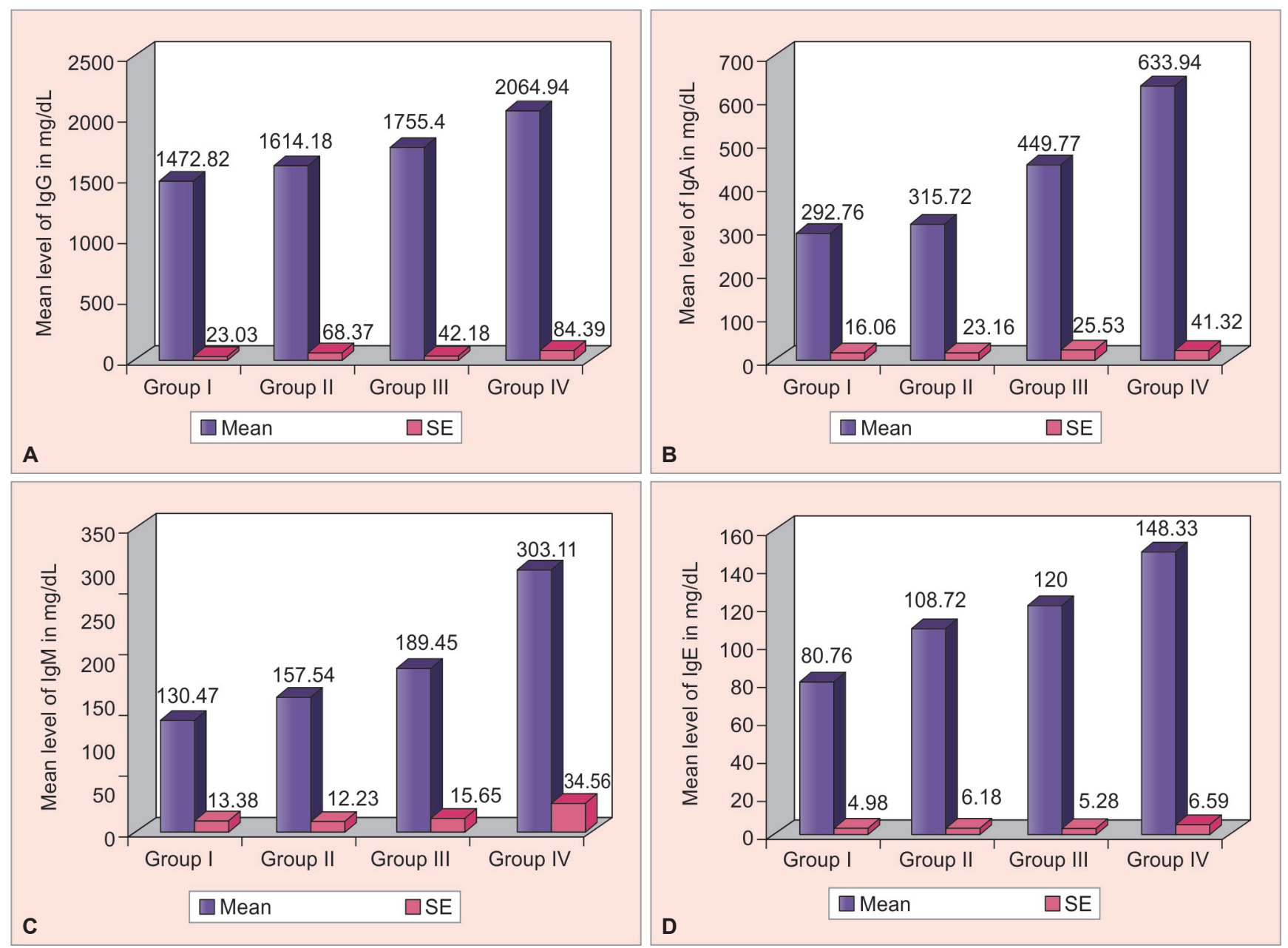

Graphs 2A to D: Serum immunoglobulin levels in healthy and oral submucous fibrosis individuals. Mean values of serum IgG $(A), \lg A(B), \lg M(C)$, and $\lg E(D)$ levels obtained in each group are expressed in $\mathrm{mg} / \mathrm{dL}$. SE: Standard error

(1614.18) showed the highest values next to group IV and the observed levels were almost similar (Graph 2A). The least level of serum IgG was observed in group I (1472.82). In case of serum IgA, the highest level was noted in group IV (633.94) when compared with all the other groups. The next highest level was observed in group III (449.77). However, the levels found in groups I (292.76) and II (315.72) were almost similar and were considered as the lowest among other groups (Graph 2B). Significantly, elevated levels of IgM were noted in group IV (303.11). The levels observed in other studied groups differed significantly from group IV. Groups I, II, and III showed similar values, group I (130.47) being the lowest (Graph 2C). Like serum IgG, $\operatorname{IgA}$, and $\operatorname{IgM}$, the level of IgE observed in group IV (148.33) was the highest among all the studied groups. The level decreased in the order $148.33>120.00>108.72>80.76$ for groups IV, III, II, and I respectively (Graph 2D).

\section{DISCUSSION}

The measurements of serum immunoglobulins provide the information about one's humoral immune status.
Hence, a routine analysis of the same is very important. Low levels of immunoglobulins indicate certain immune deficiencies and high levels provide information about chronic inflammatory diseases, hematological disorders, infection, and malignancies. ${ }^{6,7}$ In this study, we investigated the level of serum immunoglobulins at various stages of OSMF to correlate the disease severity.

The elevated level of serum IgG observed in the present study is in line with the report of Chatuvedi et al, ${ }^{8}$ Pinakapani et al, ${ }^{9}$ and Patidar et al. ${ }^{10}$ However, the results obtained in the present study oppose the observations noted by Rajendran et al. ${ }^{11}$ This elevated level of IgG in the serum of OSMF patients when compared with healthy individuals could be due to secondary infections. IgG is considered as the major antibody in secondary antibody response. Continuous exposure of oral mucosa to the areca nut components could mediate a stimulatory effect on immunoglobulin production, ${ }^{12}$ and thus the observed elevated level in the present study.

The IgA is mainly found in the mucosal secretions. It also circulates in blood and its main function in circulation is to clear immune complexes by phagocytosis. ${ }^{13}$ It 
has been reported that the production of $\operatorname{Ig} \mathrm{A}$ is regulated by transforming growth factor (TGF)- $\beta$, a multifunctional cytokine. ${ }^{14,15}$ The TGF- $\beta$ is reported to play potential roles, such as growth, differentiation, and modulation of immune responses. ${ }^{16}$ The stimulation of isotype switching to $\operatorname{Ig} \mathrm{A}$ is the well-studied ability of TGF- $\beta .^{17}$ van Ginkel et $\mathrm{al}^{18}$ reported significantly low levels of blood and mucosal IgA levels in TGF- $\beta$ knockout mice. In line with this report, elevated levels of TGF- $\beta$ and serum $\operatorname{Ig}$ A were reported in oral potentially malignant disorder called OSMF. $^{19}$

A significantly higher level of $\operatorname{IgM}$ and $\operatorname{IgE}$ observed in the present study is similar to the result reported by Gupta et $\mathrm{al}^{20}$ and Shah et $a .^{21}$ Both of these immunoglobulins increase during chronic infections. It has been reported that the patients with OSMF have limited mouth opening, hence, poor oral hygiene, which in turn harbors various microorganisms in the oral cavity. A study conducted in OSMF and healthy individuals revealed the presence of various microorganisms in which Candida species predominates. ${ }^{22}$ Especially, the presence of the strain Candida albicans has been reported in the oral premalignant conditions, such as leukoplakia and OSMF. ${ }^{23,24}$ Candidal infection is capable of inducing epithelial atypia, which leads to malignant transformation through the release of nitrosamine compounds. ${ }^{25}$ These toxins could have stimulated the immune system, and thus resulted in the elevated levels of immunoglobulins in the serum of OSMF patients.

\section{ACKNOWLEDGMENTS}

The study was supported financially by University Grants Commission - Basic Scientific Research, New Delhi. We sincerely acknowledge all the staff members at the Dept. of Oral Medicine and Radiology of Tamilnadu Govt. Dental College and Hospital, Chennai, Tamilnadu for their support towards this research work and Dr. Balasubramanian Krishnan, Former Professor of Kerala University for the statistical analysis done for the present study.

\section{CONCLUSION}

In summary, the given study shows elevated levels of serum immunoglobulins. The alteration found in the present study could be due to various factors as described in the discussion part. Since immunoglobulins are commonly used in routine clinical practice, analyses of such parameters are very much important in both diagnosis and prognosis of the disease progression. Further studies utilizing greater sample size warrant the complete mechanism behind this altered level and would help to bring out a thorough understanding of the mechanism behind it.

\section{REFERENCES}

1. Wang J, Lin D, Peng H, Huang Y, Huang J, Gu J. Cancerderived immunoglobulin $\mathrm{G}$ promotes tumor cell growth and proliferation through inducing production of reactive oxygen species. Cell Death Dis 2013 Dec;4(12):e945.

2. Lichtenstein A, Zighelboim J, Dorey F, Brossman S, Fahey JL. Comparison of immune derangements in patients with different malignancies. Cancer 1980 Apr;45(8):2090-2095.

3. Pillai R, Balaram P, Reddiar KS. Pathogenesis of oral submucous fibrosis. Relationship to risk factors associated with oral cancer. Cancer 1992 Apr;69(8):2011-2020.

4. Nair U, Bartsch H, Nair J. Alert for an epidemic of oral cancer due to use of the betel quid substitutes gutkha and pan masala: a review of agents and causative mechanisms. Mutagenesis 2004 Jul;19(4):251-262.

5. Ranganathan K, Mishra G. An overview of classification schemes for oral submucous fibrosis. J Oral Maxillofac Pathol 2006 Jan;10:55-58.

6. Buckley RH. Humoral immunodeficiency. Clin Immunol Immunopathol 1986 Jul;40(1):13-24.

7. Dispenzieri A, Gertz MA, Therneau TM, Kyle RA. Retrospective cohort study of 148 patients with polyclonal gammopathy. Mayo Clin Proc 2001 May;76(5):476-487.

8. Chatuvedi VN, Sharma AK, Chakrabarati S. Salivary coagulopathy and humoral response in oral submucous fibrosis (OSMF). J Indian Dent Assoc 1991 Mar;62(3):51-53, 59.

9. Pinakapani R, Shambulingappa P, Shashikanth MC. Salivary coagulopathy and immunoglobulins in oral submucous fibrosis. J Indian Acad Oral Med Radiol 2009 Dec;21(2):62-66.

10. Patidar KA, Parwani RN, Wanjari SP. Correlation of salivary and serum IgG, IgA levels with total protein in oral submucous fibrosis. J Oral Sci 2011 Mar;53(1):97-102.

11. Rajendran R, Sugathan CK, Remani P, Ankathil R, Vijayakumar T. Cell mediated and humoral immune responses in oral submucous fibrosis. Cancer 1986 Dec;58(12):2628-2631.

12. Salimonu LS, Mohammed I, Oyeyinka GO, Arinola OG. Basic immunology for students of medicine and biology. 2nd ed. Nigeria: College Press; 2003.

13. Woof JM, Russell MW. Structure and function relationships in IgA. Mucosal Immunol 2011 Nov;4(6):590-597.

14. Cerutti A, Cols M, Gentile M, Cassis L, Barra CM, He B, Puga I, Chen K. Regulation of mucosal IgA responses: lessons from primary immunodeficiencies. Ann N Y Acad Sci 2011 Nov;1238:132-144.

15. Banchereau J, Pascual V, O'Garra A. From IL-2 to IL-37: the expanding spectrum of anti-inflammatory cytokines. Nat Immunol 2012 Oct;13(10):925-931.

16. Wells RG. Fibrogenesis. V. TGF-b signaling pathways. Am J Physiol Gastrointest Liver Physiol 2000 Nov;279(5):G845-G850.

17. Stavnezer J, Kang J. The surprising discovery that TGF beta specifically induces the IgA class switch. J Immunol 2009 Jan;182(1):5-7.

18. van Ginkel FW, Wahl SM, Kearney JF, Kweon MN, Fujihashi K, Burrows PD, Kiyono H, McGhee JR. Partial IgA-deficiency with increased Th2-type cytokines in TGF-beta 1 knockout mice. J Immunol 1999 Aug;163(4):1951-1957.

19. Gupta S, Ghosh S, Gupta S, Sakhuja P. Effect of curcumin on the expression of p53, transforming growth factor- $B$, and inducible nitric oxide synthase in oral submucous fibrosis: a pilot study. J Investig Clin Dent 2017 Nov;8(4):e12252.

20. Gupta DS, Gupta MK, Golhar BL. Oral submucous fibrosisclinical study and management by physiofibrolysis (MWD). J Indian Dent Assoc 1980;52:375-378. 
21. Shah N, Kumar R, Shah MK. Immunological studies in oral submucous fibrosis. Indian J Dent Res 1994 Jul-Sep;5(3): 81-87.

22. Arendorf TM, Walker DM. The prevalence and intraoral distribution of Candida albicans in man. Arch Oral Biol 1980 Feb;15(1):1-10.

23. Reichart PA, Schmidtberg W, Samaranayake LP, Scheifele C. Betel quid-associated oral lesions and oral Candida species in a female Cambodian cohort. J Oral Pathol Med 2002 Sep;31(8):468-472.

24. HooperSJ,CreanSJ,LewisMA,SprattDA, WadeWG, WilsonMJ. Viable bacteria present within oral squamous cell carcinoma tissue. J Clin Microbiol 2006 May;44(5):1719-1725.

25. Sitheeque MA, Samaranayake LP. Chronic hyperplastic candidosis/candidiasis (Candidal leukoplakia). Crit Rev Oral Biol Med 2003 Jul;14(4):253-267. 